CUAD. CONTAB. / BOGOTÁ, COLOMBIA, 15 (38): 525-547 / JULIO-DICIEMBRE 2014 / 525

\title{
La potestad reglamentaria del ejecutivo de las leyes tributarias vista desde la jurisprudencia de la Corte Constitucional ${ }^{*}$
}

\author{
doi: 10.11144/Javeriana.cc15-38.prel
}

\section{Carlos Mario Restrepo-Pineda}

Maestría en derecho procesal, Universidad de Medellín.

Especialista en derecho procesal contemporáneo, Univer-

sidad de Medellín. Especialista en legislación tributa-

ria, Universidad Autónoma Latinoamericana. Abogado,

Universidad de Antioquia. Contador público, Universidad

Autónoma Latinoamericana. Tecnólogo en Sistemas,

Tecnológico de Antioquia.

Correos electrónicos: cmrp@hotmail.com;

carlosmariorestrepo@unaula.edu.co;

cmrestrepo@udem.edu.co

\footnotetext{
* Este artículo de reflexión es producto de la investigación Alcance de los decretos reglamentarios de la ley tributaria en los cuales se ha excedido la potestad reglamentaria, llevada a cabo por el grupo de investigación Pluriverso, GIP, de la Universidad Autónoma Latinoamericana, UNAULA, Medellín, Colombia, registrado en Colciencias. Este proyecto, que abarcó de julio de 2012 a julio de 2014, tenía como objetivo determinar el alcance de los decretos reglamentarios de la ley tributaria en los cuales se ha excedido la potestad reglamentaria; fue financiado por la Universidad Autónoma Latinoamericana, Medellín.
} 
Resumen La potestad reglamentaria del presidente de la República es una atribución constitucional que le permite a la rama del poder Ejecutivo del Estado expedir decretos reglamentarios, resoluciones y órdenes necesarias para el cumplimiento de las leyes; sin embargo, la jurisprudencia de la Corte Constitucional es reiterativa en indicar que en el ejercicio de esa función, no le es permitido al presidente legislar, al crear o modificar la ley, funciones que constitucionalmente le corresponden al Congreso. En materia tributaria, y en los temas que tienen reserva de ley, hay condicionamientos señalados en la Constitución que definen el alcance de la potestad reglamentaria del Ejecutivo. ¿Cuál es el alcance de la potestad reglamentaria del presidente de las leyes en materia tributaria en la jurisprudencia de la Corte Constitucional? ¿Qué pasa cuando el presidente se desborda en su potestad reglamentaria de la ley y entra a legislar? Estos son los interrogantes acerca de los cuales gira el presente artículo.

Palabras clave Potestad reglamentaria; potestad legislativa; acto administrativo; decreto reglamentario de la ley; reserva de ley; nulidad; debido proceso

\section{Código de clasificación K41, K34, H25}

\section{The Regulatory Power of the Executive Power on Tax Laws as seen from the Case Law of the Constitutional Court}

\footnotetext{
Abstract The regulatory power of the President is a constitutional power that allows the executive branch of the State issuing decrees, resolutions and orders necessary for the enforcement of laws, however the jurisprudence of the Constitutional Court is repetitive in indicating that the carrying out that task, he is not allowed the President to legislate, the law creating or modifying functions it by the Constitution to Congress. In tax matters, and issues that have reserve law, there are constraints outlined in the Constitution that define the scope of the regulatory powers of the Executive. What is the scope of the regulatory powers of the President of the laws on taxation in the juris-
}

prudence of the Constitutional Court? What happens when the President overflows in its statutory authority in entering law will legislate? These are the questions on which turn the focus of this article.

Keywords Regulatory power; legislative power; administrative act; decree of law; legal reserve; nullity; due process

\section{Potestade regulamentária do executivo das leis tributárias vista desde a jurisprudência da Corte Constitucional}

Resumo A potestade regulamentaria do presidente da República é uma atribuição constitucional que permite ao poder Executivo do Estado expedir decretos regulamentários, resoluções e ordens necessárias para o cumprimento das leis; no entanto, a jurisprudência da Corte Constitucional é reiterativa em indicar que no exercício dessa função, não é permitido o presidente legislar, ao criar ou modificar a lei, funções que constitucionalmente correspondem ao Congresso. Na questão tributária, e nos temas que têm reserva de lei, a Constituição tem indicado condicionamentos em que define o escopo da potestade regulamentaria do Executivo. Qual o escopo da potestade regulamentaria do presidente nas leis em matéria tributária na jurisprudência da Corte Constitucional? O que acontece quando o presidente desborda a sua potestade regulamentaria da lei e entra a legislar? Esses os interrogantes sobre os quais gira o presente artigo.

Palavras-chave Potestade regulamentária; potestade legislativa; ato administrativo; decreto regulamentário da lei; reserva de lei; nulidade; devido processo

\section{Introducción}

El presente artículo trata acerca de los actos administrativos en los cuales la rama del poder 
Ejecutivo del Estado representado por el presidente desborda la potestad reglamentaria de la ley y entra a legislar, al crear o modificar la ley creada por el Congreso, lo cual infringe la Constitución, pues la potestad reglamentaria tiene un carácter constitucional y está definida en el artículo 189 numeral 11 de la Constitución, al igual que la potestad legislativa tiene un carácter constitucional dado en el artículo 114 y el encabezado del artículo 150 de la Constitución. El problema se presenta cuando el Ejecutivo actúa de manera inconstitucional, al usurpar desde la autoridad administrativa la función del poder Legislativo, expedir decretos reglamentarios de la ley en materia tributaria, en los cuales desborda la potestad reglamentaria, y ante la presunción de legalidad de los actos administrativos, estos deben aplicarse, mientras no sea demandada en la jurisdicción contencioso administrativo su inconstitucionalidad, y esta no sea declarada por el juez.

Lo relevante del asunto en materia tributaria es la cantidad de principios constitucionales que se ven violentados, como el principio de representación (artículo 338 de la Constitución), que implica que no hay tributo sin representación, que es el pueblo por medio de sus representantes el que establece los tributos; el principio de certeza (artículo 338 de la Constitución), que implica que la ley debe establecer los elementos estructurales del tributo, a saber: el sujeto activo, el sujeto pasivo, el hecho gravable, la base gravable y la tarifa; el principio de tipicidad del tributo, que implica que los hechos imponibles deben estar establecidos en la ley (artículo 338 de la Constitución); el principio de legalidad del tributo que implica los principios anteriormente mencionados; la potestad legislativa del Congreso (artículo 114 y encabezado del artículo 150 de la Constitución), que implica que el Congreso es el que tiene la función constitucional de legislar; y el principio de reserva de ley (artículo 150 numeral 12 de la Constitución), que implica que hay asuntos que solo pueden ser tratados por el Congreso en leyes, y uno de esos asuntos es el de los tributos.

La inconstitucionalidad de estos decretos reglamentarios de la ley en materia tributaria expedidos por el Ejecutivo y en los que entra a legislar, es el punto central de análisis del presente escrito, el cual busca especificar el alcance que tiene el poder Ejecutivo del Estado al ejercer la potestad reglamentaria de la ley en materia tributaria en la jurisprudencia de la Corte Constitucional, además de explicitar los límites que tiene desde la Constitución la potestad reglamentaria, y lo que ocurre cuando el aspecto a reglamentar tiene reserva de ley como es el caso de los tributos.

El problema se presenta cuando el Ejecutivo legisla en materia tributaria por medio de los decretos reglamentarios y establece deberes que luego la Administración Tributaria utiliza como fundamento legal para sancionar a los contribuyentes.

El análisis se desarrolla desde cuatro lineamientos: en el primero se analiza el concepto de la potestad reglamentaria que tiene el Ejecutivo de la ley y se hace una contextualización temática enfocada en la Constitución y en las sentencias de la Corte Constitucional en las cuales se ha abordado el tema. 
En el segundo punto se definen dos aspectos: uno referente al alcance de la potestad reglamentaria del poder Ejecutivo del Estado representado por el presidente en los temas en los que hay reserva de ley como en el caso de los tributos; y el otro, si el poder Legislativo le puede dar facultades extraordinarias al Ejecutivo para que expida normas con fuerza de ley, en asuntos que tienen reserva de ley.

En el tercer punto se analiza el alcance de la potestad reglamentaria del poder Ejecutivo del Estado representado por el presidente en materia tributaria y se hace un recorrido por las sentencias de la Corte Constitucional en las cuales se ha pronunciado frente a la usurpación por parte del presidente de la función legislativa que tiene el poder Legislativo.

Y, por último, en el cuarto punto, se proponen alternativas jurídicas al problema planteado a partir de la jurisprudencia de la Corte Constitucional, en el caso de los decretos reglamentarios en los cuales el Ejecutivo desborda la potestad reglamentaria de la ley al crear deberes, y luego estos decretos reglamentarios son utilizados como el fundamento legal para sancionar a los contribuyentes por el no cumplimiento de esos deberes.

\section{La potestad reglamentaria del poder Ejecutivo de la ley}

La potestad reglamentaria de la ley está asignada constitucionalmente a la rama del poder Ejecutivo del Estado representado por el presidente y es la figura que le permite dictar reglamentos de carácter general e impersonal dirigidos a la ejecución de la ley; mediante ella lleva a cabo la labor de expedir decretos, resoluciones y órdenes necesarias para el cumplimiento de las leyes como lo ordena el numeral 11 del artículo 189 de la Constitución Nacional. Así, la potestad reglamentaria de la ley debe ser complementaria a esta y debe generar los medios necesarios para hacerla cumplir eficazmente, es decir, para lograr hacerla operativa. Jaime Ossa-Arbeláez (2000, pp. 251-255) define la potestad reglamentaria de la ley en relación con la Constitución, como aquella función que le corresponde al Ejecutivo por mandato constitucional del artículo 189 numeral 11, por la cual la administración dicta reglamentos de carácter general e impersonal dirigidos a la ejecución de la ley al adoptar los medios necesarios para hacerla cumplir eficazmente.

Corresponde al presidente como Jefe de Estado, Jefe del Gobierno y Suprema Autoridad Administrativa: [...] 11. Ejercer la potestad reglamentaria, mediante la expedición de los decretos, resoluciones y órdenes necesarios para la cumplida ejecución de las leyes (Constitución Política, 1991).

En la sentencia C-594/10, la Corte Constitucional dice que la facultad restrictiva del Congreso en lo referente a la obligación tributaria, no implica que el presidente no pueda ejercer su potestad reglamentaria, la cual es legítima y necesaria para ajustar las disposiciones generales impuestas por el Legislador a las circunstancias reales de la Nación. La potestad reglamentaria en materia tributaria tiene la función de reglamentar la ley, para hacer real el enunciado abstracto de esta. Así, el Legislador hace la ley y el Ejecutivo tiene el derecho y el deber de hacerla operativa en el plano de lo 
real. Ejercer la potestad reglamentaria de la ley por parte del Ejecutivo no implica que este esté legislando, pues el hecho de reglamentar la ley no equivale a legislar.

La facultad constitucional otorgada al presidente para expedir normas es solo de carácter reglamentario a fin de desarrollar el procedimiento o trámite requerido para el cumplimiento de una ley; por tanto, se debe tener presente que para entender la potestad reglamentaria del presidente, es pertinente abordar el tema de los límites y alcances de esta facultad planteados por la Constitución.

La sentencia C-228/93 trata el tema específico de las funciones reglamentarias del presidente en su potestad reglamentaria de la ley y aclara que las normas expedidas por el presidente en función de la facultad reglamentaria son de carácter general, están subordinadas a la ley y orientadas a permitir su aplicación, es decir, que la función del presidente en su potestad reglamentaria radica en ejecutar actos administrativos dirigidos al cumplimiento del enunciado impreciso de la ley. La Corte Constitucional interpreta que la potestad reglamentaria del Ejecutivo no le permite legislar; lo que le está permitido es regular, que es lo que hace con el decreto reglamentario. De acuerdo con la Constitución, al Ejecutivo le pueden ser conferidas facultades para legislar pero solo en casos de estados de excepción, de acuerdo con los artículos 212, 213, 214 y 215 constitucionales, o de facultades extraordinarias de acuerdo con el artículo 150 numeral 10 constitucional.

La Corte Constitucional se pronuncia en cuanto a la imposibilidad de que el Ejecutivo legisle por fuera de estados de excepción o de las facultades extraordinarias, y afirma la extensión constitucional que tiene el presidente para reglamentar la ley. En relación con esta afirmación, en la sentencia C-564/95, la Corte Constitucional dice que en el ámbito regulatorio del presidente, y en general de los funcionarios del poder Ejecutivo, no es dado ampliar, restringir o modificar el contenido de la ley; por tanto, las normas reglamentarias deben estar subordinadas a la ley respectiva, teniendo como principal finalidad la cabal ejecución de esta ${ }^{1}$.

Se puede decir que la Corte Constitucional es precisa al afirmar que el presidente no puede legislar, pues esta es una facultad propia del Legislativo, pero sí tiene campo de acción en el ámbito regulatorio, el cual está marcado por el desarrollo efectivo de las reglas consagradas en la ley, para explicitar sus contenidos, hipótesis y supuestos.

En la sentencia C-028/97, la Corte Constitucional se pronuncia acerca de la potestad reglamentaria del presidente, analiza el tema de los "límites y asuntos materia de reglamento", reitera que el ejercicio de la potestad reglamentaria es una función constitucionalmente asignada al presidente y agrega que esta función es inalienable, intransferible e inagotable, pues puede ejercerse en cualquier tiempo sin tener que ser considerada como una facultad absoluta, así como tampoco puede practicarse para alterar o modificar el contenido de la ley, ni reglamentar leyes que no ejecuta la Adminis-

\footnotetext{
1 Respecto de la subordinación a la ley de las normas reglamentarias expedidas por el Ejecutivo, la Corte Constitucional se ha pronunciado en varias sentencias: C-564/95, C-028/97, C-512/97, C-066/99, C-302/99, C-509/99, C-805/01, C-1005/08.
} 
tración y menos reglamentar materias que solo compete al Legislador reglamentar.

En la sentencia C-704/10 se refiere a los requisitos que debe cumplir el presidente para ejercer la potestad reglamentaria e indica que son dos: primero, la existencia previa de un contenido o una materia legal que pueda ser reglamentada; y segundo, el respeto por parte de la autoridad que expide la reglamentación de tal contenido, de las demás leyes y de la Constitución.

De lo expuesto, frente al tema de la potestad reglamentaria del Ejecutivo, la Corte Constitucional ha sido constante en afirmar su atribución constitucional y ha dado pistas que sirven para la interpretación del alcance de la potestad reglamentaria del Ejecutivo en materia tributaria, que aparece en los argumentos de la sentencia C-028/97, en la que se pronuncia sobre los límites de la potestad reglamentaria del Ejecutivo, al afirmar que estos límites están definidos en la ley, y sus campos de acción están supeditados por la misma ley, que estos campos no se pueden traspasar en pro de que la ley pierda su sentido, aún menos, que el poder Ejecutivo pueda reglamentar materias cuyo contenido está reservado al Legislador, y que solo el Legislativo tiene la capacidad jurisdiccional para cambiar, modificar, crear o concluir una ley. En esta sentencia, la Corte Constitucional alude a los límites de la potestad reglamentaria del Ejecutivo, al indicar que si el reglamento rebosa la ley, deberá ser declarado nulo ${ }^{2}$ por inconstitucional, posición que es ratificada en la

2 La Corte Constitucional toma de referente para la acción de nulidad la sentencia C-028/97 y la cita en la sentencia C-512/97. sentencia C-512/97, y que esta nulidad la debe declarar la autoridad judicial competente que es el Consejo de Estado, de acuerdo con el artículo 237 numeral 2 de la Constitución, es decir, no la puede declarar ni la Administración, ni ningún particular.

En el anterior párrafo se muestra un hallazgo importante para el marco de la acción jurídica a seguir cuando se rebosa la función reglamentaria del Ejecutivo, al señalar que se debe proceder a la declaración de nulidad por inconstitucional por la autoridad judicial competente. Esta acción jurídica se encuentra de igual forma en la sentencia C-290/97; allí, la Corte Constitucional dice que debe existir la ley a reglamentar para el posible ejercicio de la potestad reglamentaria y que el requisito fundamental que supone la potestad reglamentaria está establecido por la existencia previa de un contenido o materia legal por reglamentar y no en la creación de ella.

Hasta este punto, el alcance de la potestad reglamentaria y sus límites están identificados, además se ha determinado que la Corte Constitucional reconoce una acción jurídica para pronunciarse cuando el presidente se excede en el ejercicio de la potestad reglamentaria y se extralimita en sus funciones, al entrar en materia que no es de su competencia, invadir o usurpar terrenos de competencia del Legislador; esta acción se concreta con el medio de control de nulidad por inconstitucionalidad, para lo cual se debe presentar la demanda de nulidad por inconstitucionalidad ante el Consejo de Estado, el cual puede hacer la declaración de esta 
nulidad $^{3}$. De esta forma, a los actos administrativos que buscan modificar la ley, ampliarla o derogarla, extralimitándose en su función reglamentaria, se les aplicará la figura de nulidad por inconstitucionalidad del reglamento.

Ahora, en referencia al reglamento como objeto de la potestad reglamentaria, en la sentencia C-302/99, la Corte Constitucional destacó que el ejercicio de la potestad reglamentaria tiene como fin hacer que la ley sea ejecutable por medio del reglamento, el cual debe buscar que la ley sea operativa, pues es un complemento de ella y es indispensable para que se haga ejecutable. En esta sentencia, la Corte Constitucional recalcó lo establecido en el artículo 113 de la Constitución Política, al mencionar que es deber jurídico del gobierno nacional hacer cumplir de la mejor manera la ley e indicó la importancia de la cooperación de los distintos órganos del Estado para la realización de los fines estatales y de hacer cumplir la ley y que, en términos legislativos, el Legislador puede indicarle al presidente que direccione su potestad reglamentaria en temas concretos para hacer efectiva la ley.

Lo anterior significa que el Legislador puede pedirle al presidente que direccione su potestad reglamentaria sobre temas específicos, pero este direccionamiento tiene como finalidad que el presidente reglamente las leyes para su debida ejecución y cumplimiento, pues la Corte Constitucional señala que el Congreso dicta las leyes y el presidente las reglamenta, lo

3 La Corte Constitucional trabajó el tema de la declaración de nulidad por inconstitucional de la norma emanada del ejercicio de la potestad reglamentaria del presidente en las sentencias C-564/95, C-028/97, C-512/97, C-509/99, C-290/02 y C-852/05. cual lo imposibilita para actuar en materia legislativa. En relación con la función legislativa del Congreso, en la sentencia C-509/99 se cita la sentencia C-564/95 para precisar que el Congreso no puede delegar sus funciones legislativas a otros entes del Estado sin perjuicio de la colaboración armónica, pues violaría el artículo 113 de la Constitución, y tal hecho despojaría, por tanto, las disposiciones legales de su estabilidad y jerarquía.

La imposibilidad del Congreso de separarse de sus funciones legislativas, para permitirle al presidente que produzca alteraciones contrarias a la ley o a la Constitución, también es tratada en varias sentencias por la Corte Constitucional $^{4}$, que ha sido reiterativa en afirmar que la función reglamentaria le da al presidente la facultad para reglamentar leyes, pero como se ha mencionado ya en este escrito, no le permite introducir en la ley alteraciones contrarias a la voluntad del Legislador ni puede desbordar los principios de la norma de normas.

Por tanto, como lo interpreta la Corte Constitucional en la sentencia C-509/99, el único objeto del reglamento que se ha confiado al presidente en el ejercicio de su potestad reglamentaria de las leyes, consiste en lograr el cumplimiento y efectividad de la ley, por ende, es inconstitucional introducir en la ley mutaciones o alteraciones contrarias a la voluntad del Legislador; además, afirma la Corte que la potestad reglamentaria no tiene límite en el tiempo y que esta puede ser ejercida en cualquier momento siempre y cuando esté en función de hacer cumplir la ley de la mejor manera.

\footnotetext{
$4 \mathrm{Al}$ respecto, ver las sentencias C-028/97, C-512/97,

C-066/99, C-309/99, C-509/99, C-530/03.
} 
Para finalizar esta primera parte acerca de la potestad reglamentaria del poder Ejecutivo de la ley, es pertinente analizar la sentencia C-805/01, en la cual se confirman los argumentos emitidos por la Corte Constitucional frente al tema de la potestad reglamentaria del Ejecutivo $^{5}$, al interpretar que los numerales $10 \mathrm{y}$ 11 del artículo 189 de la Constitución Política, establecen para el presidente el deber de hacer cumplir la ley y de ejercer la potestad reglamentaria para su efectivo cumplimiento.

En conclusión, en cuanto a la potestad reglamentaria del poder Ejecutivo de la ley, se puede decir que el ejercicio de la potestad reglamentaria es una función constitucionalmente asignada al presidente; esta función es inalienable, intransferible e inagotable, pues puede ejercerse en cualquier tiempo y su fundamento está en el numeral 11 del artículo 189 de la Constitución.

Los decretos reglamentarios que expide el presidente en función de su facultad reglamentaria son de carácter general, están subordinados a la ley que reglamentan y orientados a permitir su aplicación, es decir, que la función del presidente en su potestad reglamentaria radica en ejecutar actos administrativos dirigidos al cumplimiento del enunciado impreciso de la ley, es decir, debe generar los medios necesarios para hacerla cumplir eficazmente, para lograr hacerla operativa.

La potestad reglamentaria tiene límites y estos límites están definidos en la ley que se reglamenta; su campo de acción está supeditado

$5 \mathrm{Al}$ respecto, ver las sentencias C-228/93, C-564/95, C-028/97, C-290/97, C-512/97, C-066/99, C-302/99, C-509/99. a ella y no se pueden traspasar en pro de que la ley pierda su sentido, no puede ejecutarse para alterar o modificar el contenido de la ley, y aún menos que el poder Ejecutivo pueda reglamentar materias cuyo contenido está reservado al Legislador, y es este el que tiene la capacidad jurisdiccional para cambiar, modificar, crear o concluir una ley.

Si el presidente se excede en su facultad reglamentaria de la ley, corresponde a la jurisdicción de lo contencioso administrativo el control de legalidad de los decretos reglamentarios respectivos, teniendo en cuenta que si estos rebasan su campo de aplicación deberán ser declarados nulos por inconstitucionales por el Consejo de Estado.

\section{Alcance de la potestad reglamentaria del presidente en los temas que tienen reserva de ley}

En esta parte del escrito se examina en la jurisprudencia de la Corte Constitucional ${ }^{6}$, el alcance de la potestad reglamentaria de la ley a partir de la cláusula general de competencia y la reserva legal, en los temas en los que hay reserva de ley, como el caso de los tributos, que de acuerdo con el artículo 150 numeral 12 de la Constitución tiene reserva de ley.

Para el desarrollo de este punto es preciso hacer la siguiente pregunta ¿qué se entiende por reserva de ley? La expresión se define des-

\footnotetext{
6 El tema se desarrolla a partir de las sentencias C-028/97, C-570/97, C-066/99, C-530/03, C-734/03, C-675/05, C-1005/08 y C-704/10 que tratan el tema de la reserva de ley.
} 
de la sentencia C-570/97, en la que la Corte Constitucional expresa que la reserva de ley es una institución jurídica de rango constitucional, que pretende obligar al Legislador a regular aquellas materias que el constituyente ha decidido que sean desarrolladas en una ley, lo que, por ende, imposibilita al poder Legislativo para delegar sus funciones a otro órgano como el Ejecutivo, lo que a su vez no permite que el Ejecutivo se pronuncie sobre materias que deben ser materia de reserva de ley.

Cabe preguntarse ahora ¿cuáles son esas materias que tienen reserva de ley? Para hacer una síntesis de la respuesta a este interrogante es procedente ver el trabajo de Eduardo Cordero-Quinzacara (2009, p. 411), sobre temas constitucionales colombianos como el de la reserva de ley que es aplicable al caso de Chile. Cordero-Quinzacara expone que los temas que tienen reserva de ley en las constituciones del siglo XIX son: en materia tributaria, la ley del presupuesto, lo referido a la expedición de grandes códigos como el penal, mercantil y procesal. Lo anterior en Colombia está consagrado en los numerales 10, 12 y $19^{7}$ del artículo 150 de la Constitución, de acuerdo con este artículo en materia de tributos hay reserva de ley (numeral 12 artículo 150), en lo referente a dar facultades extraordinarias al Ejecutivo para que expida normas con fuerza de ley, no se puede hacer en materia de impuestos (numeral 10 artículo 150) de acuerdo con la interpretación que la Corte Constitucional hace en la sentencia C-570/97 y la sentencia C-1155/08, porque es-

7 La referencia al numeral 20 que se hace en el numeral 10 del artículo 150 es un gazapo o error y está referida al numeral 19 del artículo 150. tas facultades no se pueden conferir para expedir códigos, leyes estatutarias, leyes orgánicas, ni las previstas en el numeral 19 del artículo 150, ni para decretar impuestos, de ahí que en lo referente a tasas y contribuciones el Congreso le puede conferir facultades extraordinarias al Ejecutivo para que expida normas con fuerza de ley. Pero hay que indicar que por el hecho de que el Congreso le pueda dar facultades extraordinarias de acuerdo con el artículo 150 numeral 10 al Ejecutivo para expedir normas con fuerza de ley cuando la necesidad lo exija o la conveniencia pública lo aconseje, en el caso de las tasas y contribuciones, no afecta la reserva de ley en materia de tributos establecida en el artículo 150 numeral 12, pues es la misma Constitución la que permite que se den esas facultades extraordinarias en cuanto a tasas y contribuciones, porque la prohibición es solo para los impuestos, pero por ser normas con fuerza de ley el control de constitucionalidad está a cargo de la Corte Constitucional.

En la sentencia C-704/10, la Corte Constitucional dice que su jurisprudencia ha sostenido que le corresponde al Congreso de la República, en virtud de la cláusula general de competencia legislativa, desarrollar la Constitución y dictar las leyes, y solo de manera excepcional, tal competencia estaría radicada en cabeza del Ejecutivo. Es decir, la potestad legislativa está en cabeza del poder Legislativo representado en el Congreso. En esta sentencia, la Corte Constitucional dice que en virtud de la cláusula general de competencia le corresponde al Legislador dictar las leyes, y cuando se trate de un asunto que tenga reserva legal por mandato de la Constitución, le corresponde exclusivamente al Legis- 
lador desarrollarla, pues la reserva de ley obliga al Legislador a regular aquellas materias que el constituyente decidió que fueran desarrolladas en una ley.

\section{En la sentencia C-530/03, la Corte Cons-} titucional se pronuncia frente a las materias que no están atribuidas por la Constitución a una autoridad específica y afirma que conforme a la cláusula general de competencias, se debe entender que en estos casos se trata de una materia que corresponde desarrollar principalmente al Legislador, y que este no puede atribuir de manera íntegra la reglamentación al presidente, pues se estaría desprendiendo de una competencia atribuida constitucionalmente. $\mathrm{Al}$ respecto, la Corte Constitucional recalca que la potestad reglamentaria del presidente exige para su ejercicio, que la ley haya configurado previamente una regulación o contenido legislativo y que, a partir de este, el presidente puede ejercer su función reglamentaria en pro de su debida aplicación, y en caso de que el Legislador no defina esa materialidad legislativa, es decir, materias que no están atribuidas por la Constitución a una autoridad específica, se estaría delegando al presidente lo que la Constitución ha pretendido que no sea materia de reglamento sino de ley. Luego, en la misma sentencia, la Corte Constitucional indica que hay determinadas temáticas que le corresponde desarrollar primariamente al Legislador, en virtud de su competencia, en las cuales puede delimitar el tema y permitir su concreción por medio de reglamentos administrativos; y otras temáticas en las que se tratan asuntos que son materia que tiene reserva legal, que por mandato cons- titucional, entonces corresponde exclusivamente al Legislador desarrollar.

En la sentencia C-530/03, la Corte Constitucional cita la sentencia C-508/02 en relación con la extensión del campo para el ejercicio reglamentario de la ley e indica que el Congreso determina esa extensión, y que entre más precisión y detalle tenga la ley, más se restringe el ámbito del reglamento. Esto, a su vez, significa que a mayor generalidad y falta de precisión, más se ampliará el ejercicio de la potestad reglamentaria. La Corte Constitucional interpreta que algunos de los apartados mencionados en el artículo 3 de la Ley 769 de 2002, tema de debate de la sentencia C-530/03, violan la reserva legal, y por tanto, desplazan de manera inconstitucional la competencia del Congreso al presidente; la Corte Constitucional evoca la declaración de inexequibilidad de ese apartado.

Ahora se analiza el tema de la reserva de ley ${ }^{8}$ cuando se han conferido facultades extraordinarias al presidente, de acuerdo con el artículo 150 numeral 10 de la Constitución.

En la sentencia C-734/03, la Corte Constitucional hace un estudio minucioso sobre el tema de la reserva de ley, haciendo mención a si el Presidente, actuando como Legislador extraordinario, cumplió la carga mínima de intensidad normativa, que por razón de la reserva de ley, se exige en estos casos o si, por el contrario, se atribuyó una competencia que desborda el ámbito de la potestad reglamentaria.

$8 \mathrm{Al}$ respecto de la reserva de ley en la potestad reglamentaria, se pueden consultar la Corte Constitucional en las sentencias C-570/97, C-066/99, C-530/03, C-734/03, C-675/05, C-1005/08. 
Para el análisis del caso, la Corte Constitucional señala aquellos asuntos concretos en los cuales el Congreso no puede conceder facultades extraordinarias al presidente, como aquellas a las que hace referencia el numeral 10 del artículo 150 para expedir códigos, leyes estatutarias, leyes orgánicas, ni las previstas en el numeral $20^{9}$ del presente artículo, ni para decretar impuestos. La Corte Constitucional afirma que solo por fuera de las anteriores materias es posible al Congreso conceder facultades extraordinarias al presidente $y$, por tanto, estos asuntos son las únicas materias sobre las cuales no es posible al Congreso conceder facultades extraordinarias al presidente para reglamentar.

En la sentencia C-675/05, la Corte Constitucional se pronuncia acerca de la potestad reglamentaria del presidente en materia reserva de ley; para este caso, se analiza el desbordamiento de la función reglamentaria del Ejecutivo, pues no se le otorgaron facultades extraordinarias para reglamentar aspectos del Sistema Nacional de Evaluación de la Educación. Esta materia tiene reserva de ley, por lo que el presidente se debía limitar a la precisión y especificación de elementos necesarios para la efectiva aplicación de la ley. Según la Corte Constitucional, al excederse en esta función reglamentaria, el presidente estaría sustituyendo al Legislador, ya que no hay un otorgamiento de facultades extraordinarias por parte del Congreso al presidente; por tal motivo, la Corte Constitucional señala que la potestad de regulación de la educación que el constituyente asig-

9 La referencia al numeral 20 que se hace en el numeral 10 del artículo 150 es un gazapo o error y está referida en realidad al numeral 19 del artículo 150. nó al Estado debe ser ejercida por el Legislador por tener reserva de ley.

Como se evidencia, la Corte Constitucional destaca que al existir reserva de ley en el tema, es deber del Legislador regular o indicar los criterios, los parámetros y las bases de la reglamentación, para que con este material legal, el presidente pueda ejercer la potestad reglamentaria respetando el contenido de la Constitución y de la ley reglamentada; de este modo, la Corte Constitucional insiste en la afirmación de que el poder reglamentario es un poder para desarrollar la ley.

Asimismo, se concluye acerca del alcance de las facultades extraordinarias para expedir normas con fuerza de ley por parte del Ejecutivo, en materias que tienen reserva de ley, como los asuntos indicados en el artículo 150 numeral 12 y 19 , que en estos asuntos el presidente solo puede actuar siempre y cuando el Congreso le confiera facultades extraordinarias, que estas facultades solo son conferidas cuando la necesidad lo exija o la conveniencia pública lo aconseje y que esas facultades extraordinarias son temporales. Pero hay asuntos referentes al artículo 150 numeral 10, en los que no se le pueden conceder facultades extraordinarias al presidente, como el caso de los impuestos; por tanto, en materia de impuestos no se pueden conferir estas facultades extraordinarias, pero sí se pueden conferir para tasas y contribuciones.

Por ende, el alcance del presidente en su potestad reglamentaria sobre materias que tienen reserva de ley, como el caso de los tributos, está condicionado por la misma ley y es inconstitucional que el presidente actúe sin que se le confieran esas facultades extraordinarias. 


\section{Alcance de la potestad reglamentaria del presidente en materia tributaria}

El tema a tratar ahora, en el presente escrito, es el de la potestad reglamentaria del presidente de la ley en materia tributaria, que como se ha indicado en este trabajo tiene reserva de ley; para ello se desarrollará la temática con base en los pronunciamientos que ha hecho la Corte Constitucional.

En la sentencia C-228/93, la Corte Constitucional se pronuncia acerca del tema de la potestad reglamentaria del presidente en materia tributaria, al afirmar que el Congreso tiene la facultad para establecer y modificar los tributos, pero que esto no implica que el presidente no pueda ejercer su potestad reglamentaria de la ley en este tema.

En esta sentencia, la Corte Constitucional aclara que los actos reglamentarios expedidos por el presidente deben aportar los detalles para la ejecución de la ley y facilitar su interpretación, es decir, estos actos reglamentarios deben hacer operativo el enunciado abstracto de la ley para que se pueda aplicar en el plano de lo real; por tanto, la potestad reglamentaria en materia tributaria está igualmente limitada al contenido de la ley que reglamenta, y esa facultad solo es constitucional para el presidente siempre y cuando su función sea la de reglamentar para efectuar los aspectos genéricos de la ley y hacerla cumplir. La Corte Constitucional concibe que solo bajo estos términos el presidente pueda ejercer la potestad reglamentaria de la ley en materia tributaria.
Entre los pronunciamientos que la Corte Constitucional ha hecho frente al tema de la reserva de ley en materia tributaria, se encuentran las sentencias C-594/10 y C-704/10, que serán abordadas en su orden de pronunciamiento.

En la sentencia C-594/10, la Corte Constitucional se refiere al principio de legalidad tributaria, para afirmar que solo la ley puede imponer gravámenes, limitaciones o restricciones a las personas, y que el reglamento no puede ser fuente de obligaciones, restricciones o gravámenes para las personas, sin perjuicio de las facultades especiales de regulación que se asignen a determinados entes del Estado. En esta sentencia, la Corte Constitucional cita la sentencia C-474/03, en la que trata el tema de la potestad reglamentaria, para argumentar que los artículos 114 y 150 numerales 1 y 2 de la Constitución contemplan la cláusula general de competencia para el Legislador; por un lado, el Congreso es el que tiene la potestad de desarrollar la Constitución y expedir las leyes y, por el otro, la potestad reglamentaria del presidente exige que la ley haya establecido una regulación o materia legislativa para que este pueda ejercer la función de reglamentar la ley para su debida aplicación. Ahora, en materia tributaria, en la sentencia C-594/10, la Corte Constitucional destaca que existe una reserva de ley prevista en el artículo 150 numeral 12 y el artículo 338 de la Constitución; el primero manifiesta que es el Congreso el que mediante una ley debe establecer contribuciones fiscales y contribuciones parafiscales; además, la Corte Constitucional afirma que para ese efecto se ha excluido la posibilidad de legislación de- 
legada — como las facultades extraordinarias a que hace mención el artículo 150 numeral 10 de la Constitución-. Según la Corte Constitucional, estas facultades no pueden conferirse para decretar impuestos. El segundo, el artículo 338 de la Constitución, establece el principio de predeterminación del tributo sujeto al principio de legalidad, según el cual se han de definir los elementos estructurales del tributo, lo cual exige que esa predeterminación se realice de manera clara, es decir, el sujeto activo, el sujeto pasivo, el hecho generador, la base gravable y la tarifa. Esta conclusión también se encuentra en la sentencia C-228/10.

Por tanto, se concluye que para la Corte Constitucional en las materias que tienen reserva de ley como la tributaria, la competencia es propia del Legislador en la fijación de los aspectos esenciales y definitorios del asunto sometido a reserva legal, la cual no puede ser de ningún modo diferida al reglamento, pues este solo tiene cabida en aspectos puntuales y técnicos, que no deben ser contrarios a la reserva de ley, ni constituirse como una fuente autónoma de deberes, obligaciones o limitaciones.

En la sentencia C-704/10, del 6 de septiembre de 2010, la Corte Constitucional analiza el artículo 12 numeral 11, de la Ley 1324 de 2009, que cuestionan los demandantes por conferirle al ICFES la facultad de definir elementos esenciales del tributo. Según ellos, la norma solo determinó el sujeto activo y faltaron los demás elementos: el sujeto pasivo, la base gravable, el hecho generador y la tarifa, con lo cual se violan los artículos 338 y 345 de la Constitución.

En esta sentencia, la Corte Constitucional aborda el tema de reserva de ley en materia tri- butaria e inicia con un acercamiento al principio de legalidad tributaria, entendido en primer lugar, como la exigencia de respetar la reserva de competencia de los órganos de representación para decretar, modificar o suprimir tributos; en segundo lugar, entiende que este principio tiene el sentido de una orden, dirigida a los órganos de representación ${ }^{10}$ popular facultados para establecer las contribuciones fiscales y parafiscales, para garantizar que todo acto de imposición predetermine debidamente los elementos mínimos de la obligación tributaria y, en tercer lugar, el principio de legalidad tributaria, entendido en el contexto de un Estado unitario, es equivalente a la prohibición de que las entidades territoriales establezcan contribuciones en violación a lo dispuesto en la Constitución y en la ley.

Acerca de la legitimidad de estos órganos para crear, modificar o suprimir tributos, en la Sentencia C-246 de 1995 (magistrado ponente José Gregorio Hernández Galindo, salvamento de voto Jorge Arango Mejía y aclaración de voto Carlos Gaviria Díaz), la Corte interpretó que los órganos de representación popular pluralistas no solo eran los competentes para decretar tributos, sino también para modificarlos o suprimirlos. Dijo, sobre el particular: 'es evidente que la Constitución de 1991 prohibió al Congreso conferir facultades en materia tributaria, no solamente en cuanto a la creación de im-

10 Sobre el carácter pluralista de los órganos de representación que están llamados a regular la esencia de los tributos, se pueden consultar las sentencias C-084/95 y C-569/00. 
puestos sino en punto de su modificación, los aumentos y disminuciones, la supresión y la sustitución de los mismos, ya que reservó a la Rama Legislativa la atribución de adoptar decisiones al respecto' (Corte Constitucional, Sentencia C-704/10).

Siguiendo la sentencia C-704/10, la Corte Constitucional aclara que en la interpretación del principio de legalidad tributaria se debe tener en cuenta que este principio se encuentra plasmado en la Constitución en el artículo 150 numeral 12, el cual le confiere al Congreso la facultad para establecer contribuciones fiscales y excepcionalmente parafiscales, además el artículo 338 establece que solo el Congreso, las asambleas departamentales y los concejos distritales y municipales pueden imponer contribuciones fiscales y parafiscales:

El artículo 150 numeral 12 dispone: 'corresponde al Congreso hacer las leyes. Por medio de ellas ejerce las siguientes funciones: (...) 12. Establecer contribuciones fiscales y, excepcionalmente, contribuciones parafiscales en los casos y bajo las condiciones que establezca la ley’. Por su parte, el artículo 338, en el apartado respectivo, dispone: 'en tiempo de paz, solamente el Congreso, las asambleas departamentales y los concejos distritales y municipales podrán imponer contribuciones fiscales o parafiscales' (Corte Constitucional, Sentencia C-704/10).

La sentencia C-704/10 en ningún apartado menciona que en el ejercicio de la potestad reglamentaria el presidente puede intervenir en materias que tienen reserva de ley como la tributaria; por el contrario, la Corte Constitucional afirma que solo el Congreso, las asambleas departamentales y los concejos distritales y municipales pueden imponer contribuciones fiscales y parafiscales.

Ahora, en cuanto al tema específico de los tributos se reconoce que en la Constitución se han identificado tres clases de gravámenes: los impuestos, las tasas y las contribuciones, que son todos ellos tributos; que el artículo 338 dice que la ley, las ordenanzas y los acuerdos deben fijar los sujetos activos y pasivos, los hechos, y las bases gravables y las tarifas de todos los tributos. Cuando se trata de tasas y contribuciones, la ley, las ordenanzas y los acuerdos pueden permitir que las autoridades fijen la tarifa siempre y cuando el correspondiente acto de creación tributaria establezca "el sistema y el método" para definir los costos y beneficios, y la forma de hacer su reparto. Por tanto, deja inhabilitado al presidente para que en su potestad reglamentaria intervenga al modificar, ampliar, restringir o alterar estos asuntos que tienen reserva de ley. Se puede asegurar por tanto que en materia de impuestos el presidente no tiene campo de acción en el ejercicio de la potestad reglamentaria para legislar; solo podría intervenir en asuntos que tengan reserva de ley cuando le fueren conferidas facultades extraordinarias, las cuales tienen unos requerimientos objetivos para ser asignadas, teniendo en cuenta que estas no pueden ser conferidas en materia de impuestos pero sí en materia de tasas y contribuciones, cuya competencia es propia del Legislador, y no puede transferirse a ningún ente, pues estaría en contra de la Constitución y de 
la ley, tal como lo ha explicitado la Corte Constitucional.

\section{Alternativas jurídicas a partir de la jurisprudencia de la Corte Constitucional en el caso de los decretos reglamentarios en los cuales el Ejecutivo desborda la potestad reglamentaria de la ley}

En este apartado del trabajo, se presentan las alternativas jurídicas, a partir de la jurisprudencia de la Corte Constitucional, en el caso de los decretos reglamentarios en los cuales el Ejecutivo desborda la potestad reglamentaria de la ley en materia tributaria. Con este fin se va a exponer un caso que merece especial atención con el objeto de encontrar soluciones jurídicas a la problemática planteada, con respecto a las sanciones pecuniarias, ya que con estas ocurre igual que con las normas en materia tributaria en cuanto a la reserva de ley, lo que significa que para imponer una sanción pecuniaria se requiere que la ley lo exprese; en igual forma, los tributos debe estar establecidos en la ley, la ordenanza o el acuerdo.

En la sentencia T-558/06 referente al tema de la potestad reglamentaria en materia de sanciones pecuniarias, la Corte Constitucional conoce de un acto administrativo de carácter general en el cual se violó la reserva de ley del Congreso en el tema de las sanciones pecuniarias. Esta sentencia se origina en una acción de tutela contra Electricaribe S.A. ESP, por el Decreto 1303 de 1989, con respecto a la facultad que otorgaba este de expedir actos admi- nistrativos, mediante los cuales las empresas prestadoras de servicios domiciliarios podían imponer sanciones pecuniarias a los usuarios de servicios públicos domiciliarios. El asunto es que la empresa Electricaribe S.A. ESP expidió un acto administrativo de carácter individual sancionando pecuniariamente a un usuario de los servicios públicos domiciliarios, para lo cual se fundamenta en el decreto reglamentario que estableció la sanción pecuniaria, lo cual desborda la potestad reglamentaria.

Para analizar el asunto, hay que tener en cuenta que la potestad de sancionar a los usuarios tiene el carácter de una función administrativa, la cual requiere expresa autorización del Legislativo y del ordenamiento jurídico vigente para el ámbito sancionador, pues como lo ha manifestado la Corte Constitucional en la sentencia T-558/06, no hay disposiciones legales de las cuales pueda derivarse tal potestad sancionadora a los usuarios de los servicios públicos domiciliarios en el presente caso.

En la sentencia T-558/06, la Corte Constitucional considera que la atribución de la potestad sancionatoria a los usuarios, por parte de las empresas prestadoras de servicios públicos, no era posible, pues este asunto tiene reserva de ley, lo cual no permite que se impongan sanciones pecuniarias que no estén expresamente en la ley; además, la ley actualmente vigente no confiere tal potestad a estas empresas prestadoras del servicio y, como argumenta la Corte Constitucional en dicha sentencia, la sanción pecuniaria que indebidamente se impuso podía ser objetada por medio de la acción de tutela en la medida en que vulnera los derechos funda- 
mentales de los usuarios y compromete principios y valores del Estado:

Consideró por lo tanto esta Sala de Revisión que de una interpretación sistemática del artículo 210 de la Carta Política y de las disposiciones constitucionales que regulan los servicios públicos domiciliarios, se infería que la atribución a las entidades prestadoras de potestad sancionatoria respecto de los usuarios tenía reserva de ley y que el régimen legal de los servicios públicos domiciliarios actualmente vigente no confería tal potestad a las empresas de servicios públicos domiciliarios (Corte Constitucional, Sentencia T-558/06).

En el caso que se analiza en la sentencia T-558/06 se encontró que la ley expedida por el Congreso en materia de servicios públicos no establecía sanciones pecuniarias, y dice la Corte que una prerrogativa de esta índole no puede derivarse de otras que otorga la ley objeto de este caso, y aunque hay disposiciones de carácter reglamentario, que son actos administrativos de carácter general en los que se ha facultado a ciertas entidades para imponer sanciones pecuniarias, se trata de una norma de carácter reglamentario, la cual en ningún caso puede subsanar el vacío legal que existe en la materia, y este tipo de organismo solo cuenta con una potestad reglamentaria residual y en ningún caso puede regular materia que tiene reserva de ley:

Del anterior análisis se desprende, por lo tanto, que las empresas prestadoras de servi- cios públicos domiciliarios carecen de la prerrogativa pública de imponer sanciones pecuniarias a los usuarios. Esa misma razón permite colegir que las decisiones por medio de las adoptan decisiones (sic) de esta naturaleza no constituyen actos administrativos, sino meras vías de hecho, las cuales son impugnables por medio de la acción de tutela, máxime cuando estén en juego los derechos fundamentales de los usuarios.

[...] tal como se sostuvo en la sentencia T-720 de 2005, y se reitera en esta decisión la naturaleza misma de la potestad sancionatoria sobre los usuarios exige su regulación legal, por lo tanto no puede tener fundamento en normas de carácter reglamentario.

Como corolario de lo anterior las decisiones de las empresas de servicios públicos domiciliarios que imponen sanciones pecuniarias a los usuarios pueden constituirse en actuaciones susceptibles de ser impugnadas por medio de la acción de tutela en la medida que infrinjan el ordenamiento constitucional y adicionalmente vulneren los derechos fundamentales de los usuarios y comprometan principios y valores fundantes del Estado social de derecho colombiano (Corte Constitucional, Sentencia T-558/06).

Lo importante es la figura de la ineficiencia parcial del acto administrativo de carácter general, en este caso el decreto reglamentario, que aunque se presuma su legalidad, no produciría efecto cuando el acto administrativo de carácter particular se fundamente en él y sea impugnado por medio de la acción de tutela. En este caso, el acto administrativo de carácter 
particular en el que se sancionó al usuario pide su impugnación vía tutela por violar derechos fundamentales como el debido proceso, pues el decreto reglamentario de carácter general no puede ser fuente de sanciones en asuntos que tienen reserva de ley; de ahí que se considere una vía de hecho sancionar no fundamentándose en la ley sino en el decreto reglamentario de carácter general habiendo reserva de ley. Ahora, como se vio en los capítulos precedentes, el acto administrativo de carácter general, en este caso el decreto reglamentario, debe ser demandado ante la jurisdicción contenciosa administrativa haciendo uso del medio de control de nulidad por inconstitucionalidad, para que esta sea declarada por el juez del Consejo de Estado en caso de proceder la nulidad por inconstitucionalidad.

La anterior es la posición de la Corte Constitucional expresada en la sentencias T-558/06 y T-720/05. De ahí que el acto administrativo de carácter particular sancionatorio se puede impugnar con acción de tutela, pues este acto constituye una vía de hecho, por tratarse de una sanción no establecida en la ley en un asunto que tiene reserva legal, lo cual viola el debido proceso.

En materia tributaria, lo anterior implica que si el presidente en un decreto reglamentario de la ley, crea o modifica elementos estructurales del tributo violando la reserva de ley en esta materia, y luego mediante un acto administrativo de carácter particular, y si la Administración de Impuestos pretende sancionar a los sujetos pasivos, fundamentándose en el decreto reglamentario que creó o modificó los elementos estructurales del tributo violando la reserva de ley, las consecuencias serían:

- El acto administrativo de carácter general, es decir, el decreto reglamentario en el que creó o modificó el tributo es violatorio de la Constitución, pues viola los siguientes artículos de la Constitución: el artículo 114, el artículo 150 encabezado y numerales 1 , 2, 10 y 12, y el artículo 338, en cuanto a los principios de legalidad, de representación y de certeza de los tributos; la reserva de ley en materia tributaria; y la prohibición al Congreso para darle facultades extraordinarias al Ejecutivo para expedir normas con fuerza de ley para decretar impuestos. Por todo lo anterior, un decreto reglamentario de la ley, que crea o modifica los elementos estructurales del tributo violando la reserva de ley que hay en esta materia, está viciado de nulidad por inconstitucionalidad, y se debe demandar ante el Consejo de Estado de acuerdo con el artículo 237 numeral 2 de la Constitución.

- El acto administrativo de carácter particular con el cual la Administración de Impuestos pretende sancionar al sujeto pasivo, fundamentándose en el decreto reglamentario que creó o modificó los elementos estructurales del tributo violando la reserva de ley, se puede impugnar con la acción de tutela, porque sancionar fundamentándose en el decreto reglamentario y no en el texto de la ley constituye una vía de hecho y viola derechos fundamentales como el debido proceso, ya que el acto sancionatorio debe estar respaldado en la ley y no en el decreto reglamentario que creó o modificó los ele- 
mentos estructurales del tributo violando la reserva de ley. Hay que tener en cuenta que los impuestos deben estar decretados en la ley, y que el presidente no debe legislar en materia tributaria, incluso le está prohibido el Congreso darle facultades extraordinarias para expedir normas con fuerza de ley para decretar impuestos.

En conclusión, el alcance de la potestad reglamentaria del presidente en materia tributaria se ajusta a la Constitución, si en su ejercicio se limita al contenido de la ley que reglamenta, reglamentándola para efectuar los aspectos genéricos de la ley y hacerla cumplir, la Corte Constitucional concibe que solo bajo estos términos el presidente puede ejercer la potestad reglamentaria de la ley en materia tributaria.

En materias que tienen reserva de ley como la tributaria, la competencia es propia del Legislador en la fijación de los aspectos esenciales y definitorios del asunto sometido a reserva legal, la cual no puede ser de ningún modo diferida al reglamento, pues este solo tiene cabida en aspectos puntuales y técnicos, que no deben ser contrarios a la reserva de ley, ni constituirse como una fuente autónoma de deberes, obligaciones o limitaciones.

En materia tributaria, el presidente no tiene campo de acción para afectar la ley en el ejercicio de la potestad reglamentaria; el presidente solo podrá intervenir en materia tributaria cuando le fueren conferidas facultades extraordinarias en cuanto a tasas y contribuciones, pero las facultades extraordinarias no pueden ser conferidas en materia de impuestos. La facultad reglamentaria tiene límites para ejercerse en materias con reserva de ley como la tributaria, cuya competencia es propia del Legislador, y no puede transferirse a ningún ente, pues estaría en contra de la Constitución y de la ley, como lo ha explicitado la Corte Constitucional.

En cuanto a la solución que se presenta a la problemática planteada en esta investigación en materia tributaria, cuando el Ejecutivo excede la potestad reglamentaria de la ley al entrar a legislar es la siguiente:

- La rama del poder Ejecutivo del Estado representada por el presidente tiene la potestad reglamentaria de la ley tributaria; si en el decreto reglamentario referente a tributos, rebosa su campo de aplicación, al entrar a legislar o a modificar la ley, este decreto reglamentario debe ser declarado nulo por inconstitucional, nulidad que debe ser declarada por la autoridad judicial competente, para lo cual ha de demandarse haciendo uso del medio de control de nulidad por inconstitucionalidad.

- Cuando un decreto reglamentario referente a tributos está viciado de inconstitucionalidad por rebosar su campo de aplicación y en él se ha legislado o se ha modificado la ley, y luego es utilizado por la Administración Tributaria con el objeto de sancionar a un contribuyente, ese acto sancionatorio constituiría una vía de hecho, pues aunque esté vigente el decreto reglamentario y se deba aplicar por presunción de legalidad, los textos que rebosaron su campo de aplicación porque en ellos se legisló o se modificó la ley vigente en materia tributaria son ineficaces parcialmente, pues son violatorios de la reserva de ley que rige en materia tributaria; por tanto, violan el debido proceso, 
pues la fuente de la sanción no es la ley sino un decreto reglamentario, pero su ineficacia no aplica de pleno derecho, pues se ha de impugnar con acción de tutela el acto sancionatorio expedido por la administración tributaria basándose en los textos inconstitucionales del decreto reglamentario.

\section{Conclusiones}

La potestad reglamentaria es una función constitucional asignada al presidente; es inalienable, intransferible, inagotable y la puede ejercer en cualquier tiempo. Su ejercicio exige que la ley haya configurado previamente una regulación o contenido legislativo, a partir del cual el presidente pueda ejercer su función reglamentaria en pro de su debida aplicación.

En el ejercicio de la potestad reglamentaria de la ley, el Ejecutivo no puede reglamentar leyes que no ejecuta la Administración, ni por medio de decretos reglamentarios legislar en materias cuyo contenido está reservado al Legislador. Si el Ejecutivo en el decreto reglamentario desborda su campo de aplicación, este último está viciado de nulidad por inconstitucional, nulidad que debe ser declarada por la autoridad judicial competente, es decir, el Consejo de Estado de acuerdo con el artículo 237 numeral 2 de la Constitución.

La reserva de ley es una institución jurídica de rango constitucional que obliga al Legislador a regular las materias que el constituyente ha querido que sean desarrolladas en una ley. Por tanto, si se trata de una materia que tiene reserva legal, por mandato de la Constitución le corresponde al Legislador desarrollarla.
La reserva de ley en materia tributaria está establecida en el artículo 150 numeral 12 de la Constitución. La reserva de ley no permite que el Ejecutivo mediante decretos reglamentarios de la ley cree, modifique o elimine la ley tributaria, ya que son asuntos que deben ser materia de ley, pero el mismo artículo 150 en el numeral 10 dispone que el Congreso puede dar facultades extraordinarias en forma temporal al Ejecutivo para que expida normas con fuerza de ley, pero ese mismo numeral consagra la prohibición de darle facultades extraordinarias al presidente para expedir normas con fuerza de ley para decretar impuestos, lo que imposibilita al poder Legislativo para delegar la función legislativa en el Ejecutivo cuando se trata de decretar impuestos. Lo que sí puede hacer el Congreso es darle facultades extraordinarias al Ejecutivo para expedir normas con fuerza de ley para decretar tasas y contribuciones.

El decreto reglamentario que desborda la ley en materia tributaria es inconstitucional, pues viola los siguientes artículos de la Constitución: el artículo 114 y el encabezado junto con los numerales 1 y 2 del artículo 150 que disponen la potestad legislativa en el Legislador; el artículo 150 numerales 10 y 12 que establecen la reserva de ley en materia tributaria y la prohibición al Congreso de conceder poderes extraordinarios al Ejecutivo para decretar impuestos por medio de actos que tengan la fuerza de la ley; y el artículo 338, en cuanto al principio de legalidad, el principio de representación y el principio de certeza de los tributos. Además, viola el artículo 345, si con tal deposición se perciben tributos que no figuren en el presupuesto de rentas. 
Por tanto, un decreto reglamentario de la ley en materia tributaria, que crea o modifica los elementos estructurales del tributo, lo cual viola la reserva de ley que rige en esta materia, está viciado de nulidad por inconstitucionalidad y se debe demandar ante el Consejo de Estado según el artículo 237 numeral 2 constitucional haciendo uso del medio de control de nulidad por inconstitucionalidad, para que el Consejo de Estado se pronuncie respecto de su constitucionalidad.

Desde el derecho procesal, la solución que se presenta a la problemática planteada en materia tributaria en el presente artículo, cuando el Ejecutivo desborda la potestad reglamentaria de la ley establecida en el artículo 189 numeral 11 constitucional, al entrar a legislar y usurpando de esta forma la potestad legislativa del Congreso establecida en el artículo 114, el encabezado y los numerales 1 y 2 del artículo 150 de la Constitución, y en un asunto que tiene reserva de ley de acuerdo con el artículo 150 numeral 12 constitucional, es la siguiente:

- La rama del poder Ejecutivo del Estado, representada por el presidente, tiene la potestad reglamentaria de la ley tributaria; si el decreto reglamentario, en esta materia, rebosa su campo de aplicación, al entrar a legislar o a modificar la ley, debe ser demandado, utilizando el medio de control de nulidad por inconstitucionalidad, solicitando su nulidad por inconstitucional, nulidad que debe ser declarada por la autoridad judicial competente, en este caso el Consejo de Estado.

- Cuando un decreto reglamentario en materia tributaria está viciado de inconstitucio- nalidad por rebosar su campo de aplicación y en él se ha legislado o ha modificado la ley, y luego estos textos que han desbordado la ley son utilizados por la Administración Tributaria con el objeto de sancionar a un contribuyente en un acto administrativo de carácter individual, ese acto sancionatorio constituiría una vía de hecho, pues aunque esté vigente el decreto reglamentario y no se haya demandado su nulidad y gozando de la presunción de legalidad, los textos que rebosaron su campo de aplicación, porque en ellos se legisló o se modificó la ley vigente son ineficaces parcialmente, pues son violatorios de la reserva de ley que rige en esta materia, pero su ineficacia no aplica de pleno derecho, pues se ha de impugnar con acción de tutela el acto administrativo de carácter particular sancionatorio expedido por la administración tributaria basándose en los textos inconstitucionales del decreto reglamentario, pues constituye una vía de hecho fundamentar el acto administrativo de carácter particular en los textos violatorios de la reserva de ley del decreto reglamentario, pues viola el principio de tipicidad que establece que el fundamento legal de la sanción debe estar en la ley y no en un decreto reglamentario, lo cual viola el derecho fundamental al debido proceso y constituye una vía de hecho impugnable mediante acción de tutela.

\section{Referencias}

Colombia (1991). Constitución Política.

Disponible en: http://www.alcaldiabogota. 
gov.co/sisjur/normas/Norma1.jsp?i $=4125$

http://www.secretariasenado.gov.co/index. php/leyes-y-antecedentes/constitucion-ysus-reformas

Colombia (1989). Decreto 1303 de 1989, por el cual se establece el régimen de suspensiones del servicio eléctrico y las sanciones pecuniarias por el uso no autorizado o fraudulento del mismo. Diario Oficial, 38.865, 20 de junio de 1989. Disponible en: http://apolo.creg.gov.co/Publicac.nsf/ f7599f8065183c5c05256eee006fd3a0/b1a alacd30e1fb900525785a007a6e64?OpenD ocument

Colombia (2002). Ley 769 de 2002, por la cual se expide el Código Nacional de Tránsito Terrestre y se dictan otras disposiciones. Diario Oficial, 44.893, 7 de agosto de 2002; Diario Oficial, 44.932, 13 de septiembre de 2002. Disponible en: http://www.alcaldiabogota. gov.co/sisjur/normas/Norma1.jsp?i=5557 Colombia (2009). Ley 1324 de 2009, por la cual se fijan parámetros y criterios para organizar el sistema de evaluación de resultados de la calidad de la educación, se dictan normas para el fomento de una cultura de la evaluación, en procura de facilitar la inspección y vigilancia del Estado y se transforma el ICFES. Diario Oficial, 47.409, 13 de julio de 2009. Disponible en: http://www.alcaldiabogota. gov.co/sisjur/normas/Norma1.jsp?i=36838

Cordero-Quinzacara, Eduardo (2009) El sentido actual del dominio legal y la potestad reglamentaria. Revista de Derecho de la Pontificia Universidad Católica de Valparaíso, 32, 409440. http://www.scielo.cl/scielo. php?script $=$ sci_arttext\&pid $=$ S071868512009000100012\&lng=es\&nrm=iso Corte Constitucional (1993). Sentencia C-228/93, 17 de junio de 1993. Magistrado ponente Vladimiro Naranjo-Mesa. Disponible en: http:// www.corteconstitucional.gov.co/ relatoria/1993/C-228-93.htm

Corte Constitucional (1995). Sentencia C-084/95, 1 de marzo de 1995. Magistrado ponente Alejandro MartínezCaballero. Disponible en: http:// www.corteconstitucional.gov.co/ relatoria/1995/C-084-95.htm

Corte Constitucional (1995). Sentencia C-246/95, 1 de junio de 1995. Magistrado ponente José Gregorio HernándezGalindo. Disponible en: http:// www.corteconstitucional.gov.co/ relatoria/1995/C-246-95.htm Corte Constitucional (1995). Sentencia C-564/95, 30 de noviembre de 1995. Magistrado ponente José Gregorio Hernández-Galindo. Disponible en: http://www.corteconstitucional.gov.co/ relatoria/1995/C-564-95.htm

Corte Constitucional (1997). Sentencia C-028/97, 30 de enero de 1997. Magistrado ponente Alejandro MartínezCaballero. Disponible en: http:// www.corteconstitucional.gov.co/ relatoria/1997/C-028-97.htm

Corte Constitucional (1997). Sentencia C-290/97, 16 de junio de 1997. Magistrado ponente Jorge Arango-Mejía. Disponible en: http:/www.corteconstitucional.gov.co/ relatoria/1997/C-290-97.htm 
Corte Constitucional (1997). Sentencia

C-512/97, 9 de octubre de 1997. Magistrado ponente Jorge Arango-Mejía. Disponible en: http://www.corteconstitucional.gov.co/ relatoria/1997/C-512-97.htm

Corte Constitucional (1997). Sentencia C-570/97, 6 de noviembre de 1997. Magistrado ponente Carlos Gaviria-Díaz. Disponible en: http:// www.corteconstitucional.gov.co/ relatoria/1997/C-570-97.htm

Corte Constitucional (1999). Sentencia C-066/99, 10 de febrero de 1999. Magistrados ponentes Fabio Morón-Díaz, Alfredo Beltrán-Sierra. Disponible en: http://www.corteconstitucional.gov.co/ relatoria/1999/C-066-99.htm

Corte Constitucional (1999). Sentencia C-302/99, 5 de mayo de 1999. Magistrado ponente Carlos Gaviria-Díaz. Disponible en: http://www.corteconstitucional.gov.co/ relatoria/1999/C-302-99.htm

Corte Constitucional (1999). Sentencia C-509/99, 14 de julio de 1999. Magistrado ponente José Gregorio Hernández-Galindo. Disponible en: http://www.corteconstitucional.gov.co/ relatoria/1999/C-509-99.htm

C-569/00 Corte Constitucional (1999). Sentencia C-569/00, 17 de mayo de 2000. Magistrado ponente Carlos Gaviria-Díaz. Disponible en: http:// www.corteconstitucional.gov.co/ relatoria/2000/C-569-00.htm

Corte Constitucional (2001). Sentencia C-805/01, 1 de agosto de 2001. Magistrado ponente Rodrigo Escobar-Gil. Disponible en: http://www.corteconstitucional.gov.co/ relatoria/2001/C-805-01.htm

Corte Constitucional (2002). Sentencia

C-290/02, 23 de abril de 2002. Magistrado ponente Clara Inés VargasHernández. Disponible en: http:// www.corteconstitucional.gov.co/ relatoria/2002/C-290-02.htm

Corte Constitucional (2003). Sentencia C-474/03, 10 de junio de 2003. Magistrado ponente Eduardo Montealegre-Lynett. Disponible en: http:/www.corteconstitucional.gov.co/ relatoria/2003/C-474-03.htm

Corte Constitucional (2003). Sentencia C-530/03, 3 de julio de 2003. Magistrado ponente Eduardo MontealegreLynett. Disponible en: http:// www.corteconstitucional.gov.co/ relatoria/2003/C-530-03.htm

Corte Constitucional (2003). Sentencia C-734/03, 26 de agosto de 2003. Magistrado ponente Álvaro Tafur-Galvis. Disponible en: http://www.corteconstitucional.gov.co/ relatoria/2003/C-734-03.htm

Corte Constitucional (2005). Sentencia C-675/05, 30 de junio de 2005. Magistrado ponente Jaime Araújo-Rentería. Disponible en: http://www.corteconstitucional.gov.co/ relatoria/2005/C-675-05.htm

Corte Constitucional (2005). Sentencia C-852/05, 17 de agosto de 2005. Magistrado ponente Rodrigo Escobar-Gil. Disponible en: http://www.corteconstitucional.gov.co/ relatoria/2005/C-852-05.htm

Corte Constitucional (2008). Sentencia C-1005/08, 15 de octubre de 2008. 
Magistrado ponente Humberto Antonio Sierra-Porto. Disponible en: http:// www.corteconstitucional.gov.co/ relatoria/2008/C-1005-08.htm

Corte Constitucional (2008). Sentencia C-1155/08, 26 de noviembre de 2008. Magistrado ponente Jaime AraújoRentería. Disponible en: http:// www.corteconstitucional.gov.co/ relatoria/2008/C-1155-08.htm Corte Constitucional (2008). Sentencia C-228/10, 24 de marzo de 2010. Magistrado ponente Luis Ernesto Vargas-Silva. Disponible en: http:// www.corteconstitucional.gov.co/ relatoria/2010/c-228-10.htm

Corte Constitucional (2010). Sentencia C-594/10, 27 de julio de 2010. Magistrado ponente Luis Ernesto Vargas-Silva. Disponible en: http:// www.corteconstitucional.gov.co/ relatoria/2010/C-594-10.htm Corte Constitucional (2010). Sentencia C-704/10, 6 de septiembre de 2010. Magistrado ponente María Victoria Calle-Correa. Disponible en: http:// www.corteconstitucional.gov.co/ relatoria/2010/C-704-10.htm
Corte Constitucional (2006). Sentencia T-720/05, 7 de julio de 2007. Magistrado ponente Humberto Antonio Sierra-Porto. Disponible en: http:// www.corteconstitucional.gov.co/ relatoria/2005/T-720-05.htm

Corte Constitucional (2006). Sentencia T-558/06, 18 de julio de 2006. Magistrado ponente Humberto Antonio Sierra-Porto. Disponible en: http:// www.corteconstitucional.gov.co/ relatoria/2006/T-558-06.htm

Ossa-Arbeláez, Jaime (2000). Derecho administrativo sancionador. Bogotá: Legis.

- Fecha de recepción: 28 de febrero de 2014

- Fecha de aceptación: 29 de mayo de 2014

- Disponible en línea: 01 de julio de 2014

\section{Para citar este artículo}

Restrepo-Pineda, Carlos Mario (2014). La potestad reglamentaria del ejecutivo de las leyes tributarias vista desde la jurisprudencia de la Corte Constitucional. Cuadernos de Contabilidad, 15 (38), 525-547. doi: 10.11144/Javeriana.cc15-38.prel 
